\title{
A New Exponentially Fitted Numerical Integration Scheme for Solving Singularly Perturbed Two Point Boundary Value Problems
}

\author{
MOHAMMAD JAVED ALAM \\ National Institute of Technology, \\ Jamshedpur \\ Department of Mathematics \\ India-831014 \\ javed.2014rsma002@nitjsr.ac.in
}

\author{
HARI SHANKAR PRASAD \\ National Institute of Technology, \\ Jamshedpur \\ Department of Mathematics \\ India-831014 \\ hsprasad.math@nitjsr.ac.in
}

\author{
RAKESH RANJAN \\ National Institute of Technology, \\ Jamshedpur \\ Department of Mathematics \\ India-831014 \\ 90.ranjan@gmail.com
}

\begin{abstract}
This article is concerned with an exponentially fitted numerical integration method based on uniform mesh for solving singularly perturbed two point boundary value problems. Exact and approximate rule of integration with finite difference approximation of first derivatives are used to derive a three term scheme. Theory of singular perturbation is used to introduce a fitting factor in the derived scheme. Thomas algorithm is employed to solve the resulting tridiagonal system of equations. Convergence of the proposed method is also analyzed. Solutions of several linear and nonlinear example problems are presented in terms of maximum absolute errors (MAE) to show the applicability of the proposed scheme. It is easily observed that the proposed method is able to approximate the solution very well.
\end{abstract}

Key-Words: Singular perturbation problems, Boundary value problems, Stability and convergence, Numerical Integration

Received: July 2, 2020. Revised: December 1, 2020. Accepted: December 19, 2020. Published: December 28, 2020.

\section{Introduction}

Differential equations where the highest order derivative is multiplied by an arbitrarily small parameter known as the singular perturbation parameter. These problems are arise frequently in the applied sciences and engineering, typical examples include Navier-Stokes flow problems involving high Reynolds number [1,2,3], mathematical models of liquid crystal materials and chemical reactions, control theory, electrical networks[4,5,6]. These problems have been received a significant amount of attention in past and recent years. It is a known fact that the solution of these types of problems exhibit sharp boundary layers or interior layers when the value of is taken very small, i.e., the solution exhibits rapid variation near the layer region while in regular region it varies slowly. Typically thin transition layers are present where the solutions can jump abruptly, while away from the layers the solution exhibits regular behaviour and varies slowly. So it becomes extremely difficult to solve singularly perturbed problems as severe complications have to be confronted to obtain numerical solutions accurately. Thus solution techniques which are more efficient with simpler computations are needed to solve singular perturbation problems. Readers may consult the books: $[7,8,9,10,11]$ for a detailed analytical discussion on various methods to solve singular perturbation problems. Also, recent books $[12,13,14,3,15]$ and their corresponding references present some numerical methods and their convergence analysis. In the recent past, the authors in $[16,17]$ have suggested exponentially fitted finite difference methods on uniform mesh for solving model equation of the form (1). Reddy and Mohapatra[16] have pre- sented an efficient numerical method with exponentially fitted factor to obtain the solution of singularly perturbed two point boundary value problems exhibiting boundary layer at one end point (either left or right). Gbsl Soujanya et al.[18] have developed an exponentially fitted non-symmetric finite difference method to solve singularly perturbed problems with layer behaviour using Numerovs method. Articles[19,20,21,22,23] propose different numerical approaches combining fitted mesh methods and fitted operator methods employed by several researchers for solving SPPs where as Kadalbajoo and Kumar[24] presents a detailed outline on the numerical methods for solving SPPs. But these existing numerical methods are mostly based on fitted operator techniques or use reasonable theoretical information regarding the solutions which forms a limitation of these approaches. Ranjan and Prasad[25] have presented an efficient method of numerical integration for a class of singularly perturbed two point boundary value problem at one end point (either left or right). Ranjan, Prasad and Alam[26] have developed a simple method of numerical integration for a class of singularly perturbed two point boundary value problems at one end point (either left or right). Ranjan and Prasad[27] have propose a fitted finite difference scheme for solving singularly perturbed two point boundary value problems having boundary layer at left or right end points.

The main purpose of this paper is to present computationally a new exponentially fitted numerical integration scheme for solving singularly perturbed two-point boundary value problems(SPTPBVP) having boundary layer at left or right end points of the interval considered. In this pa- 
per we have presented fitted schemes using the usual rule of evaluating exact and approximate value of the definite integral with finite difference approximation of derivatives to solve a class of SPTPBVP. The computational results show that the present method is capable of producing accurate results with minimal computational effort when perturbation parameter for any fixed value of the mesh size.

The rest of the paper is organized as follows: Some assumptions on the statement of the continuous problem is given in Section 2. In Subsection 2.1 and Subsection 2.2 , we present in detail the construction of the numerical method having boundary layer at left and right end points of the underlying interval respectively. A study of the convergence analysis is presented in Section 3. In Section 4, some numerical examples are presented to show the applicability and the effectiveness of the proposed method. The numerical results are reported with the maximum absolute error in tables. Finally, the conclusion is given in Section 5 . The paper ends with the references.

\section{Statement of the problem}

In this paper, we consider the second order singularly perturbed problem of the form:

$$
\varepsilon y^{\prime \prime}(x)+\alpha(x) y^{\prime}(x)+\beta(x) y(x)=\gamma(x) ; 0 \leq x \leq 1
$$

subject to the interval and boundary conditions

$$
y(0)=\eta \text { and } y(1)=\delta
$$

where $\varepsilon(0<\varepsilon<<1)$ is a perturbation parameter and $\eta, \delta$ are known finite constants. Also it is assumed that $\alpha(x), \beta(x), \gamma(x)$ are sufficiently smooth and bounded functions on $[0,1]$ along with $\beta(x) \leq 0$ throughout of the interval $[0,1]$. If we assume that $\alpha(x) \geq W>0$ throughout the interval $[0,1]$, where $W$ is a positive constant, the equation (1) along with (2) has a unique solution $y(x)$ with boundary layer at $x=0$ i.e. at left end point of the interval for small values of $\varepsilon$, while the boundary layer will be present in the neighbourhood of $x=1$ if $\alpha(x) \leq W<0$ throughout the interval $[0,1]$, where $W$ is a negative constant.

The operator $L_{\tau}=\varepsilon \frac{d^{2}}{d x^{2}}+\alpha(x) \frac{d}{d x}+\beta(x)$ in (1) satisfies the following minimum principle [17].

Lemma 2.1. Suppose $\omega(x)$ represents a smooth function satisfying the conditions $\omega(0) \geq 0, \omega(1) \geq 0$. Then $L_{\tau} \omega(x) \leq 0, \forall x \in(0,1)$ implies $\omega(x) \geq 0, \forall x \in[0,1]$. proof : Let $m \in[0,1]$ be such that $\omega(m)<0$ and $\omega(m)=\min _{x \in[0,1]} \omega(x)$. Clearly $m \notin\{0,1\}$, therefore $\omega^{\prime}(m)=0$ and $\omega^{\prime \prime}(m) \geq 0$. Hence, we obtain

$$
L_{\tau} \omega(m)=\varepsilon \omega^{\prime \prime}(m)+\alpha(m) \omega^{\prime}(m)+\beta(m) \omega(m)>0,
$$

which contradicts our assumption. Hence it is proved that $\omega(m) \geq 0$ and thus $\omega(x) \geq 0 \forall x \in[0,1]$.
Lemma 2.2. Let $y(x)$ be the solution of the problem (1) and (2) then we have

$$
\|y\| \leq a_{2}^{-1}\|\gamma\|+\max \left(\left|\eta_{0}\right|,|\delta|\right) .
$$

where $\|\cdot\|$ is the $L_{\infty}$ norm given by $\|y\|=\max _{0 \leq x \leq 1}|y(x)|$. proof : Let $\omega^{ \pm}(x)$ be two barrier functions defined by

$$
\omega^{ \pm}(x)=a_{2}^{-1}\|\gamma\|+\max \left(\left|\eta_{0}\right|,|\delta|\right) \pm y(x)
$$

Then this implies

$$
\begin{aligned}
& \begin{array}{l}
\omega^{ \pm}(0) \\
=a_{2}^{-1}\|\gamma\|+\max \left(\left|\eta_{0}\right|,|\delta|\right) \pm y(0) \\
=a_{2}^{-1}\|\gamma\|+\max \left(\left|\eta_{0}\right|,|\delta|\right) \pm \eta_{0} \text { since, } y(0)=\eta(0)=\eta_{0} \\
\geq 0
\end{array} \\
& \begin{aligned}
\omega^{ \pm}(1) & =a_{2}^{-1}\|\gamma\|+\max \left(\left|\eta_{0}\right|,|\delta|\right) \pm y(1) \\
& =a_{2}^{-1}\|\gamma\|+\max \left(\left|\eta_{0}\right|,|\delta|\right) \pm \delta \text { since, } y(1)=\delta \\
& \geq 0
\end{aligned} \\
& \begin{aligned}
\Rightarrow L_{\tau} \omega^{ \pm}(x) & =\varepsilon\left(\omega^{ \pm}(x)\right)^{\prime \prime}+\alpha(x)\left(\omega^{ \pm}(x)\right)^{\prime}+\beta(x) \omega^{ \pm}(x) \\
& =\beta(x)\left[a_{2}^{-1}\|\gamma\|+\max \left(\left|\eta_{0}\right|,|\delta|\right)\right] \pm L_{\tau} y(x) \\
& =\beta(x)\left[a_{2}^{-1}\|\gamma\|+\max \left(\left|\eta_{0}\right|,|\delta|\right)\right] \pm \gamma(x) \text { using }(1)
\end{aligned}
\end{aligned}
$$

As $\beta(x) \leq-a_{2}<0$ implies $\beta(x) a_{2}^{-1} \leq-1$ and since $\|\gamma\| \geq \gamma(x)$, we have

$\Rightarrow L_{\tau} \omega^{ \pm}(x) \leq(-\|\gamma\| \pm \gamma(x))+\beta(x) \max \left(\left|\eta_{0}\right|,|\delta|\right) \leq 0, \forall x \in[0,1]$.

Thus using the minimum principle we obtain, $\omega^{ \pm}(x) \geq$ $0, \forall x \in[0,1]$. Now for computing the error that has occurred in our numerical approximations, the derivative of the solution $y(x)$ should possess a boundedness which remains valid for all $x \in(0,1]$.

With the help of Lemma 2.1, the required estimate is obtained.

\subsection{Description of the method for left-end boundary layer problems}

First, equation (1) can be written in the given form:

$$
\begin{aligned}
& {\left[A(x) y^{\prime}(x)\right]^{\prime}-A^{\prime}(x) y^{\prime}(x)+y^{\prime}(x)+C(x) y(x)} \\
& =H(x) ; \quad 0 \leq x \leq 1
\end{aligned}
$$

where $A(x)=\frac{\varepsilon}{\alpha(x)}, C(x)=\frac{\beta(x)}{\alpha(x)}, H(x)=\frac{\gamma(x)}{\alpha(x)}$.

Consider the partition $0=x_{0}<x_{1}<x_{2}, \ldots,<x_{N-1}<$ $x_{N}=1$ of the interval $[0,1]$ with the uniform mesh size $h$ defined by the relation $x_{i}=x_{0}+i h$, for $i=0,1,2, \ldots, N$. Integrate equation $(3)$ in the interval $\left[x_{i}, x_{i+1}\right]$ and rearrange to get:

$$
\begin{aligned}
& A\left(x_{i+1}\right) y^{\prime}\left(x_{i+1}\right)-A\left(x_{i}\right) y^{\prime}\left(x_{i}\right)-A^{\prime}\left(x_{i+1}\right) \\
& y\left(x_{i+1}\right)+A^{\prime}\left(x_{i}\right) y\left(x_{i}\right)+\int_{x_{i}}^{x_{i+1}} A^{\prime \prime}(x) y(x) d x+ \\
& y\left(x_{i+1}\right)-y\left(x_{i}\right)+\int_{x_{i}}^{x_{i+1}} C(x) y(x) d x= \\
& \int_{x_{i}}^{x_{i+1}} H(x) d x
\end{aligned}
$$


Now, apply trapezoidal rule of Integration on the equation (5) to get:

$$
\begin{aligned}
& A\left(x_{i+1}\right) y^{\prime}\left(x_{i+1}\right)-A\left(x_{i}\right) y^{\prime}\left(x_{i}\right)-A^{\prime}\left(x_{i+1}\right) y\left(x_{i+1}\right) \\
& +\frac{h}{2}\left[A^{\prime \prime}\left(x_{i}\right) y\left(x_{i}\right)+A^{\prime \prime}\left(x_{i+1}\right) y\left(x_{i+1}\right)\right] \\
& +A^{\prime}\left(x_{i}\right) y\left(x_{i}\right)+\frac{h}{2}\left[C\left(x_{i}\right) y\left(x_{i}\right)+C\left(x_{i+1}\right) y\left(x_{i+1}\right)\right] \\
& +y\left(x_{i+1}\right)-y\left(x_{i}\right)=\frac{h}{2}\left[H\left(x_{i}\right)+H\left(x_{i+1}\right)\right]
\end{aligned}
$$

Use the first order backward/forward finite difference approximations: $y^{\prime}\left(x_{i+1}\right)=\frac{\left(y\left(x_{i+1}\right)-y\left(x_{i}\right)\right)}{h}$ and $y^{\prime}\left(x_{i}\right)=$ $\frac{\left(y\left(x_{i}\right)-y\left(x_{i-1}\right)\right)}{h}$ and notations: $y\left(x_{i}\right)=y_{i}, y\left(x_{i+1}\right)=$ $y_{i+1}, A\left(x_{i}\right)=A_{i}, C\left(x_{i}\right)=C_{i}, \alpha\left(x_{i}\right)=\alpha_{i}$ etc. in equation $(6)$, we obtain the scheme:

$$
\begin{aligned}
& \frac{1}{h}\left[A_{i+1} y_{i+1}-A_{i+1} y_{i}-A_{i} y_{i}+A_{i} y_{i-1}\right]- \\
& A_{i+1}^{\prime} y_{i+1}+A_{i}^{\prime} y_{i}+\frac{h}{2}\left[A_{i}^{\prime \prime} y_{i}+A_{i+1}^{\prime \prime} y_{i+1}\right]-y_{i}+ \\
& y_{i+1}+\frac{h}{2}\left[C_{i} y_{i}+C_{i+1} y_{i+1}\right]=\frac{h}{2}\left[H_{i}+H_{i+1}\right]
\end{aligned}
$$

Now, fitting factor $\sigma(\rho)$ is introduced into equation (7) to get:

$$
\begin{aligned}
& \frac{\sigma(\rho)}{\rho}\left[\left\{\frac{1}{\alpha_{i+1}} y_{i+1}-\frac{1}{\alpha_{i+1}} y_{i}-\frac{1}{\alpha_{i}} y_{i}+\frac{1}{\alpha_{i}} y_{i-1}\right\}-\right. \\
& h\left\{\left(\frac{1}{\alpha_{i+1}}\right)^{\prime} y_{i+1}-\left(\frac{1}{\alpha_{i}}\right)^{\prime} y_{i}\right\}+ \\
& \left.\frac{h^{2}}{2}\left\{\left(\frac{1}{\alpha_{i}}\right)^{\prime \prime} y_{i}+\left(\frac{1}{\alpha_{i+1}}\right)^{\prime \prime} y_{i+1}\right\}\right]+y_{i+1}-y_{i}+ \\
& \frac{h}{2}\left[C_{i} y_{i}+C_{i+1} y_{i+1}\right]=\frac{h}{2}\left[H_{i}+H_{i+1}\right]
\end{aligned}
$$

where $\rho=\frac{h}{\varepsilon}$ and $\sigma(\rho)$ is the fitting factor which can be determined in such a way that the solution of equation (8) converges uniformly to the solution equations (1) and (3).

Taking limits as $h \rightarrow 0$, we obtain

$$
\begin{aligned}
& \frac{\sigma(\rho)}{\rho \alpha(0)} \lim _{h \rightarrow 0}[y(i h+h)-2 y(i h)+y(i h-h)]+ \\
& \quad \lim _{h \rightarrow 0}[y(i h+h)-y(i h)]=0
\end{aligned}
$$

under the assumption that the expression $\left[A_{i}^{\prime} y_{i}-A_{i+1}^{\prime} y_{i+1}\right]+\frac{1}{2}\left[A_{i}^{\prime \prime} y_{i}+A_{i+1}^{\prime \prime} y_{i+1}\right]+$ $\frac{1}{2}\left[C_{i} y_{i}+C_{i+1} y_{i+1}\right]$ and $\frac{1}{2}\left[H_{i}+H_{i+1}\right]$ are bounded.

It is well known that the solutions of equation (1) with equation (2) is of the following form (cf.[10], pp.22-26):

$$
y(x)=y_{0}(x)+\frac{\alpha(0)}{\alpha(x)}\left(\alpha-y_{0}(0)\right) e^{-\int_{0}^{x}\left(\frac{\alpha(x)}{\varepsilon}-\frac{\beta(x)}{\alpha(x)}\right) d x}+o(\varepsilon)
$$

where $y_{0}(x)$ is the solution of the reduced problem:

$$
\alpha(x) y_{0}^{\prime}(x)+\beta(x) y_{0}(x)=\gamma(x) ; y_{0}(1)=\delta
$$

Under the consideration of Taylor's series expansions for $\alpha(x)$ and $\beta(x)$ about the point ${ }^{\prime} x=0^{\prime}$ upto their first terms only, the equation(10) becomes:

$$
y(x)=y_{0}(x)+\left(\alpha-y_{0}(0)\right) e^{-\left(\frac{\alpha(0)}{\varepsilon}-\frac{\beta(0)}{\alpha(0)}\right) x}+o(\varepsilon)
$$

Further, considering equation (12) at the point $x=x_{i}=$ $i h, i=0,1,2, \ldots, N$ and taking the limit as $h \rightarrow 0$ we obtain

$$
\lim _{h \rightarrow 0} y(i h)=y_{0}(0)+\left(\alpha-y_{0}(0)\right) e^{-\left(\frac{\alpha^{2}(0)-\varepsilon \beta(0)}{\alpha(0)}\right) i \rho}+o(\varepsilon)
$$

where $\rho=h / \varepsilon$.

Using the equation (13) for $y(i h-h), y(i h), y(i h+h)$ in equation (9) and then simplifying, we get the value of the fitting factor as

$$
\sigma(\rho)=\frac{\alpha(0) \rho}{2}\left[\frac{e^{-\left(\frac{\alpha^{2}(0)-\varepsilon \beta(0)}{\alpha(0)}\right) \frac{\rho}{2}}}{\sinh \left(\left(\frac{\alpha^{2}(0)-\varepsilon \beta(0)}{\alpha(0)}\right) \frac{\rho}{2}\right)}\right]
$$

Finally, by making use of equation (8) and $\sigma(\rho)$ given by equation (14), we can get the following three-term recurrence relationship of the form:

$$
E_{i} y_{i-1}-F_{i} y_{i}+G_{i} y_{i+1}=R_{i}, \quad(i=1,2,3, \ldots, N-1)
$$

where

$$
\begin{aligned}
& E_{i}=\frac{\sigma A_{i}}{h} \\
& F_{i}=1+\frac{\sigma\left(A_{i+1}+A_{i}\right)}{h}-\sigma A_{i}^{\prime}-\frac{h \sigma A_{i}^{\prime \prime}}{2}-\frac{h C_{i}}{2} \\
& G_{i}=1+\frac{\sigma A_{i+1}}{h}-\sigma A_{i+1}^{\prime}+\frac{h \sigma A_{i+1}^{\prime \prime}}{2}+\frac{h C_{i+1}}{2} \\
& R_{i}=\frac{h}{2}\left[H_{i}+H_{i+1}\right]
\end{aligned}
$$

Equation (15) gives a system of $(N-1)$ equations with $(N-1)$ unknowns $y_{1}$ to $y_{N-1}$. These $(N-1)$ equations together with the equation (2) are sufficient to solve the tridiagonal system by using Thomas Algorithm also called 'Discrete Invariant Imbedding algorithm'.

\subsection{Description of the method for right-end boundary layer problems}

Now, integrating equation $(3)$ in $\left[x_{i-1}, x_{i}\right]$ and rearranging we obtain:

$$
\begin{aligned}
& A\left(x_{i}\right) y^{\prime}\left(x_{i}\right)-A\left(x_{i-1}\right) y^{\prime}\left(x_{i-1}\right)-A^{\prime}\left(x_{i}\right) y\left(x_{i}\right)+ \\
& A^{\prime}\left(x_{i-1}\right) y\left(x_{i-1}\right)+\int_{x_{i}}^{x_{i}} A^{\prime \prime}(x) y(x) d x+y\left(x_{i}\right) \\
& -y\left(x_{i-1}\right)+\int_{x_{i-1}}^{x_{i}} C(x) y(x) d x=\int_{x_{i-1}}^{x_{i}} H(x) d x
\end{aligned}
$$

Evaluate the integrals in equation (17) using trapezoidal rule of Integration to get:

$$
\begin{aligned}
& A\left(x_{i}\right) y^{\prime}\left(x_{i}\right)-A\left(x_{i-1}\right) y^{\prime}\left(x_{i-1}\right)-A^{\prime}\left(x_{i}\right) y\left(x_{i}\right)+ \\
& A^{\prime}\left(x_{i-1}\right) y\left(x_{i-1}\right)+y\left(x_{i}\right)+\frac{h}{2}\left[A^{\prime \prime}\left(x_{i-1}\right) y\left(x_{i-1}\right)+\right. \\
& \left.A^{\prime \prime}\left(x_{i}\right) y\left(x_{i}\right)\right]-y\left(x_{i-1}\right)+\frac{h}{2}\left[C\left(x_{i-1}\right) y\left(x_{i-1}\right)+\right. \\
& \left.C\left(x_{i}\right) y\left(x_{i}\right)\right]=\frac{h}{2}\left[H\left(x_{i-1}\right)+H\left(x_{i}\right)\right]
\end{aligned}
$$

Using the finite difference approximations of first derivatives: $y^{\prime}\left(x_{i}\right)=\frac{\left(y\left(x_{i+1}\right)-y\left(x_{i}\right)\right)}{h}$ and $y^{\prime}\left(x_{i-1}\right)=$ $\frac{\left(y\left(x_{i}\right)-y\left(x_{i-1}\right)\right)}{h}$ and the following notations: $y\left(x_{i}\right)=$ $y_{i}, y\left(x_{i-1}\right)=y_{i-1}, A\left(x_{i}\right)=A_{i}, C\left(x_{i}\right)=C_{i}, \alpha\left(x_{i}\right)=$ $\alpha_{i}$ etc. in equation (18), we obtain the scheme:

$$
\begin{aligned}
& \frac{1}{h}\left[A_{i} y_{i+1}-A_{i} y_{i}-A_{i-1} y_{i}+A_{i-1} y_{i-1}\right]- \\
& A_{i}^{\prime} y_{i}+A_{i-1}^{\prime} y_{i-1}+\frac{h}{2}\left[A_{i-1}^{\prime \prime} y_{i-1}+A_{i}^{\prime \prime} y_{i}\right]+y_{i}- \\
& y_{i-1}+\frac{h}{2}\left[C_{i-1} y_{i-1}+C_{i} y_{i}\right]=\frac{h}{2}\left[H_{i-1}+H_{i}\right]
\end{aligned}
$$

noindent Introducing the fitting factor $\sigma(\rho)$ into equation (19), we obtain

$$
\begin{aligned}
& \frac{\sigma(\rho)}{h}\left[A_{i} y_{i+1}-A_{i} y_{i}-A_{i-1} y_{i}+A_{i-1} y_{i-1}+\right. \\
& \left.h\left[A_{i-1}^{\prime} y_{i-1}-A_{i}^{\prime} y_{i}\right]+\frac{h^{2}}{2}\left[A_{i-1}^{\prime \prime} y_{i-1}+A_{i}^{\prime \prime} y_{i}\right]\right]+ \\
& y_{i}-y_{i-1}+\frac{h}{2}\left[C_{i-1} y_{i-1}+\quad C_{i} y_{i}\right]=\frac{h}{2}\left[H_{i-1}+H_{i}\right]
\end{aligned}
$$


$y_{x_{0}}=\eta ; y_{x_{N}}=\delta$ And, the fitting factor $\sigma(\rho)$ is to be determined in such a way that the solution of equation (20) converges uniformly to the solution equations (1) and (2). Now, taking limits as $h \rightarrow 0$ we obtain

$$
\begin{aligned}
& \lim _{h \rightarrow 0} \sigma(\rho) A(i h)[y(i h+h)-2 y(i h)+y(i h-h)] \\
& +\lim _{h \rightarrow 0}[y(i h)-y(i h-h)]=0
\end{aligned}
$$

where $\left[A_{i-1}^{\prime} y_{i-1}-A_{i}^{\prime} y_{i}\right]+\frac{1}{2}\left[A_{i-1}^{\prime \prime} y_{i-1}+A_{i}^{\prime \prime} y_{i}\right]+$ $\frac{1}{2}\left[C_{i-1} y_{i-1}+C_{i} y_{i}\right]$ and $\frac{1}{2}\left[H_{i}+H_{i-1}\right]$ are bounded functions.

It is well known that the solutions of equations (1) with (2) is of the following form (cf.[10], pp.22-26):

$$
\begin{aligned}
& y(x)=y_{0}(x)+\frac{\alpha(1)}{\alpha(x)}\left(\alpha-y_{0}(1)\right) e^{\int_{x}^{1}\left(\frac{\alpha(x)}{\varepsilon}-\frac{\beta(x)}{\alpha(x)}\right) d x} \\
& +o(\varepsilon)
\end{aligned}
$$

where $y_{0}(x)$ represents the solution of the reduced problem:

$$
\alpha(x) y_{0}^{\prime}(x)+\beta(x) y_{0}(x)=\gamma(x) ; y_{0}(1)=\eta
$$

Expanding $\alpha(x)$ and $\beta(x)$ in equation (21) with the help of the Taylor's series about the point ' $x=1^{\prime}$ and restricting to their first terms, we obtain:

$$
y(x)=y_{0}(x)+\left(\gamma-y_{0}(1)\right) e^{\left(\frac{\alpha(1)}{\varepsilon}-\frac{\beta(1)}{\alpha(1)}\right)(1-x)}+o(\varepsilon)
$$

Further, considering equation (23) at the point $x=x_{i}=$ $i h, i=0,1,2, \ldots, N$ and taking the limit as $h \rightarrow 0$ we obtain

$$
\lim _{h \rightarrow 0} y(i h)=y_{0}(0)+\left(\gamma-y_{0}(1)\right) e^{\left(\frac{\alpha^{2}(1)-\varepsilon \beta(1)}{\alpha(1)}\right)\left(\frac{1}{\varepsilon}-i \rho\right)}+o(\varepsilon)
$$

where $\rho=h / \varepsilon$.

Using the equation (25) for $y(i h-h), y(i h), y(i h+h)$ in equation (21) and then simplifying, we get the value of the fitting factor as

$$
\sigma(\rho)=\frac{\alpha(1) \rho}{2}\left[\frac{e^{-\left(\frac{\alpha^{2}(1)-\varepsilon \beta(1)}{\alpha(1)}\right) \frac{\rho}{2}}}{\sinh \left(\left(\frac{\alpha^{2}(1)-\varepsilon \beta(1)}{\alpha(1)}\right) \frac{\rho}{2}\right)}\right]
$$

Finally, by making use of equation $(26)$ and $\sigma(\rho)$ given by equation $(20)$, we can get the following three-term recurrence relationship of the form:

$$
E_{i} y_{i-1}-F_{i} y_{i}+G_{i} y_{i+1}=R_{i},(i=1,2,3, \ldots, N-1)
$$

where

$$
\begin{aligned}
& E_{i}=-1+\frac{\sigma A_{i-1}}{h}+\sigma A_{i-1}^{\prime}+\frac{h \sigma A_{i+1}^{\prime \prime}}{2}+\frac{h C_{i-1}}{2} \\
& F_{i}=-1+\frac{\sigma\left(A_{i-1}+A_{i}\right)}{h}+\sigma A_{i}^{\prime}-\frac{h \sigma A_{i}^{\prime \prime}}{2}-\frac{h C_{i}}{2} \\
& G_{i}=\frac{\sigma A_{i}}{h} \\
& R_{i}=\frac{h}{2}\left[H_{i}+H_{i+1}\right]
\end{aligned}
$$

Equation (27) gives a system of $(N-1)$ equations with $(N-1)$ unknowns $y_{1}$ to $y_{N-1}$. These $(N-1)$ equations together with the equation (2) are sufficient to solve the tridiagonal system by using Thomas Algorithm also called 'Discrete Invariant Imbedding algorithm'.

\section{Convergence}

In this section, we discuss the convergence analysis of the method. Writing the tri-diagonal system of equation (27) in matrix-vector form[28], we get

$$
D Y=M
$$

where $D=\left(u_{i, j}\right), 1 \leq i, j \leq N-1$ is a tri-diagonal matrix of order $N-1$, with

$$
\begin{aligned}
& u_{i, i+1}=-\left[\sigma A_{i+1}+h-h \sigma A_{i+1}^{\prime}+\frac{h^{2} C_{i+1}}{2}+\frac{h^{2} \sigma A_{i+1}^{\prime \prime}}{2}\right] \\
& u_{i, i}=\left[\sigma A_{i+1}+\sigma A_{i}+h-h \sigma A_{i}^{\prime}-\frac{h^{2} C_{i}}{2}-\frac{h^{2} \sigma A_{i}^{\prime \prime}}{2}\right] \\
& u_{i, i-1}=-\left[\sigma A_{i}\right]
\end{aligned}
$$

and $M=\left(d_{i}\right)$ is a column vector with $d_{i}=$ $-\frac{h^{2}}{2}\left[H_{i}+H_{i+1}\right]$, where $i=1,2, \ldots, N-1$ with local truncation error:

$$
\tau_{i}(h)=\frac{h^{2}}{2}\left[C_{i}^{\prime} y_{i}+C_{i} y_{i}^{\prime}+y_{i}^{\prime \prime}-H_{i}^{\prime}\right]+o\left(h^{3}\right.
$$

we also have

$$
D \bar{Y}-\tau(h)=M
$$

where $\bar{Y}=\left(\overline{Y_{0}}, \overline{Y_{1}}, \overline{Y_{2}}, \ldots, \overline{Y_{N}}\right)^{t}$ denotes the actual solution and $\tau(h)=\left(\tau_{1}(h), \tau_{2}(h), \ldots, \tau_{N}(h)\right)^{t}$ is the local truncation error. From the equations (28) and (30), we have

$$
D(\bar{Y}-Y)=\tau(h)
$$

Thus, we obtained the error equation is

$$
D E=\tau(h)
$$

where $E=\bar{Y}-Y=\left(e_{0}, e_{1}, e_{2}, \ldots, e_{N}\right)^{t}$.

Let $Y_{i}$ be the sum of elements of $i^{\text {th }}$ row of $D$, then we have

$$
\begin{aligned}
& Y_{1}=\sum_{i=1}^{N-1} u_{1, j}=\sigma A_{1} \\
& -h\left(\sigma A_{1}^{\prime}-\sigma A_{2}^{\prime}\right)-\frac{h^{2}}{2}\left(C_{1}+C_{2}+\sigma A_{1}^{\prime \prime}+\sigma A_{2}^{\prime \prime}\right) \\
& \quad Y_{N-1}=\sum_{j=1}^{N-1} u_{N-1, j}=\sigma A_{N} \\
& \quad+h\left(1-\sigma A_{N-1}^{\prime}\right)-\frac{h^{2}}{2}\left(C_{N-1}+\sigma A_{N-1}^{\prime \prime}\right) \\
& Y_{i}=\sum_{j=1}^{N-1} u_{i, j}=h\left[\sigma A_{i+1}^{\prime}-\sigma A_{i}^{\prime}\right]-\frac{h^{2}}{2}\left[C_{i}+\right. \\
& \left.C_{i+1}+\sigma A_{i}^{\prime \prime}+\sigma A_{i+1}^{\prime \prime}\right]=h V_{i}+o\left(h^{2}\right) ; i=2(1) N-2
\end{aligned}
$$

where $V_{i}=\left[\sigma A_{i+1}^{\prime}-\sigma A_{i}^{\prime}\right]$.

Since $0<\varepsilon<<1$; for sufficiently small $h$ the matrix $D$ is irreducible and mono-tone. Hence $D^{-1}$ exists and $D^{-1} \geq 0$. Hence, from the error equation (32) we have

$$
\begin{gathered}
E=D^{-1} \tau(h) \\
\|E\| \leq\left\|D^{-1}\right\|\|\tau(h)\|
\end{gathered}
$$

Let $u_{k, i}$ be the $(k, i)^{t h}$ elements of $D^{-1}$ : Since $\bar{u}_{k, i} \geq 0$, from the theory of matrices we have,

$$
\sum_{i=1}^{N-1} \bar{u}_{k, i} Y_{i}=1 ; k=1,2, \ldots, N-1
$$


Therefore, it follows that

$$
\sum_{i=1}^{N-1} \bar{u}_{k, i} \leq \frac{1}{\min _{0 \leq i \leq N-1} Y_{i}}=\frac{1}{h V_{i_{0}}} \leq \frac{1}{h\left\|V_{i_{0}}\right\|}
$$

for some $i_{0}$ lies between 1 and $N-1$.

Now, we define $\left\|D^{-1}\right\|=\max _{0 \leq i \leq N-1} \sum_{i=1}^{N-1}\left|\bar{u}_{k, i}\right|$ and $\|\tau(h)\|=\max _{0 \leq i \leq N-1}|\tau(h)|$.

Therefore, from the equations (29), (33) and (34), we obtain

$$
e_{j}=\sum_{i=1}^{N-1} \bar{u}_{k, i} \tau_{i}(h) ; j=1(1) N-1
$$

and therefore

$$
\left|e_{j}\right| \leq \frac{k h^{2}}{h\left|V_{i_{0}}\right|} ; j=1(1) N-1
$$

where $k=\left[\frac{C_{i}^{\prime}}{2}\left|y_{i}\right|+\frac{C}{2}\left|y_{i}^{\prime}\right|+\frac{1}{2}\left|y_{i}^{\prime \prime}\right|-\frac{H_{i}^{\prime}}{2}\right]$ is constant independent of $h$.

Therefore, using the definitions and equation (35), we have

$$
\|E\|=o(h)
$$

This implies that the scheme (15) derived for the solution of left layer problems is of first order convergence on uniform mesh.

\section{Numerical illustrations}

In this section, the numerical results of some test problems are chosen.

\subsection{Numerical example problems with left- end boundary layer}

To demonstrate the applicability of proposed method computationally for left-end boundary layer problems, we have considered the following one linear and one non-linear model test problems:

Example 01 : Consider the following constant coefficient non-homogeneous singular perturbation problem from [8]:

$$
\begin{aligned}
& \varepsilon y^{\prime \prime}(x)+y^{\prime}(x)=1+2 x ; x \in[0,1] \\
& \text { with boundary conditions } y(0)=0 \text { and } y(1)=1 \text {. }
\end{aligned}
$$

The exact solution of this example is given by: $y(x)=$ $x(x+1-2 \varepsilon)+\frac{(2 \varepsilon-1)\left(1-e^{-x / \varepsilon}\right)}{\left(1-e^{-1 / \varepsilon}\right)}$ which has a boundary layer at the left side of the domain near $x=0$. Clearly, the MAE presented in Table- 3 for problem- 1 show that the present scheme is capable of producing uniformly convergent solution in case when $\varepsilon$ tends to zero for any fixed value of the step size $h=1 / N$. The comparison in MAE for Problem 1 with the existing methods in $[16,17,18]$ for various values of $\varepsilon$ and grid point $N$ is presented in Tables
1 and 2.

Example 02 : Consider the following non-linear singular perturbation problem from ([11], p. 463, Eq.(9.7.1))

$$
\varepsilon y^{\prime \prime}(x)+y^{\prime}(x)+e^{(y(x))}=0 ; x \in[0,1]
$$$$
\text { with boundary conditions } y(0)=0 \text { and } y(1)=0 \text {. }
$$

The linear problem concerned to this example is:

$$
\begin{aligned}
& \varepsilon y^{\prime \prime}(x)+2 y^{\prime}(x)+\frac{2}{x+1} y(x)=\frac{2}{x+1}\left[\ln \left(\frac{2}{x+1}\right)-1\right] \\
& x \in[0,1]
\end{aligned}
$$

The uniform valid approximation of Bender and Orszag ([11], P. 463, Eq. (9.7.6)) is

$y(x)=\ln \left(\frac{2}{x+1}\right)-\ln (2) e^{-2 x / \varepsilon}$, which has a boundary layer of thickness $o(\varepsilon)$ near $x=0$. Clearly, the MAE presented in Table-5 for problem- 2 show that the present scheme is capable of producing uniformly convergent solution in case when $\varepsilon$ tends to zero for any fixed value of the step size $h=1 / N$. The comparison in MAE for Problem 1 with the existing methods[29,17] for various values of $\varepsilon$ and grid point $N$ is presented in Tables 4 .

\subsection{Numerical example problems with right- end boundary layer}

To demonstrate the applicability of proposed method computationally for right-end boundary layer problems, we have considered the following one linear model test problem:

Example 03 : Consider the following homogeneous singular perturbation problem from $[16,17,18]$ :

$$
\varepsilon y^{\prime \prime}(x)-y^{\prime}(x)-(1+\varepsilon) y(x)=0 ; x \in[0,1]
$$

with boundary conditions $y(0)=1+\exp (-(1+\varepsilon) / \varepsilon)$ and $y(1)=1+1 / e$.

The exact solution is given by: $y(x)=\exp (-x)+$ $\exp [(1+\varepsilon)(x-1) / \varepsilon]$, which has a boundary layer at the right side of the domain near $x=1$. Clearly, the MAE presented in Table- 8 for problem- 3 show that the present scheme is capable of producing uniformly convergent solution in case when $\varepsilon$ tends to zero for any fixed value of the step size $h=1 / N$. The comparison in MAE for Problem 1 with the existing methods in $[16,17,18]$ :for various values of $\varepsilon$ and grid point $N$ is presented in Tables 6 and 7 .

\section{Conclusion}

We have derived an exponentially fitted tri-diagonal scheme for solving singularly perturbed two-point boundary value problems with boundary layer at one end points(left or right). Derived scheme is applied on four standard model example problems for different values of $N=1 / h$ and perturbation parameter $\varepsilon$. Computational results are presented in tables and compared with the existing 
Table 1: Comparison of computational results (MAE) with existing results for various values of $\varepsilon$ and $N$ for example problem1.

\begin{tabular}{l|lll|lll}
\hline & \multicolumn{3}{|c|}{$\varepsilon=10^{-4}$} & \multicolumn{3}{c}{$\varepsilon=10^{-8}$} \\
\hline$N \downarrow$ & $\begin{array}{l}\text { Mohapatra and } \\
\text { Mahalik[16] }\end{array}$ & $\begin{array}{l}\text { Mohapatra and } \\
\text { Reddy[17] }\end{array}$ & Our Result & $\begin{array}{l}\text { Mohapatra and } \\
\text { Mahalik[16] }\end{array}$ & $\begin{array}{l}\text { Mohapatra and } \\
\text { Reddy[17] }\end{array}$ & Our Result \\
\hline 16 & $5.8414 \mathrm{e}-2$ & $5.8414 \mathrm{e}-2$ & $1.8746 \mathrm{E}-04$ & $5.8591 \mathrm{e}-2$ & $5.8591 \mathrm{e}-2$ & $0.0000 \mathrm{E}+00$ \\
\hline 32 & $3.0087 \mathrm{e}-2$ & $3.0087 \mathrm{e}-2$ & $1.9372 \mathrm{E}-04$ & $3.0274 \mathrm{e}-2$ & $3.0274 \mathrm{e}-2$ & $0.0000 \mathrm{E}+00$ \\
\hline 64 & $1.5169 \mathrm{e}-3$ & $1.5169 \mathrm{e}-3$ & $1.9687 \mathrm{E}-04$ & $1.5389 \mathrm{e}-2$ & $1.5389 \mathrm{e}-2$ & $0.0000 \mathrm{E}+00$ \\
\hline 128 & $7.5535 \mathrm{e}-3$ & $7.5535 \mathrm{e}-3$ & $1.9842 \mathrm{E}-04$ & $7.7512 \mathrm{e}-3$ & $7.7512 \mathrm{e}-3$ & $0.0000 \mathrm{E}+00$ \\
\hline 256 & $3.6920 \mathrm{e}-3$ & $3.6920 \mathrm{e}-3$ & $1.9920 \mathrm{E}-04$ & $3.8923 \mathrm{e}-3$ & $3.8923 \mathrm{e}-3$ & $0.0000 \mathrm{E}+00$ \\
\hline 512 & $1.7547 \mathrm{e}-3$ & $1.7547 \mathrm{e}-3$ & $1.9956 \mathrm{E}-04$ & $1.9497 \mathrm{e}-3$ & $1.9497 \mathrm{e}-3$ & $0.0000 \mathrm{E}+00$ \\
\hline
\end{tabular}

Table 2: Comparison of computational results(MAE) with existing results [with fitting factor(w.f.f.) and without fitting factor(w.o.f.f.)] for various values of $\varepsilon$ and $N$ for example problem-1.

\begin{tabular}{l|ll|ll|ll|ll}
\hline & \multicolumn{9}{|l|}{$\varepsilon=10^{-3}$} & \multicolumn{2}{l}{$\varepsilon=10^{-5}$} \\
\hline & $\begin{array}{l}\text { SOUJANYA } \\
\text { et.al. [18] }\end{array}$ & & & \multicolumn{2}{l}{$\begin{array}{l}\text { Our Result } \\
\text { et.al. [18] }\end{array}$} & & & \\
\hline$N \downarrow$ & with f.f & w.o. f.f & with f.f & w.o. f.f & with f.f & w.o. f.f & with f.f & without f.f \\
\hline 8 & $1.07 \mathrm{e}-001$ & 15.41 & $1.75 \mathrm{E}-03$ & $7.92 \mathrm{E}-03$ & $1.09 \mathrm{e}-001$ & $1.56(+3)$ & $1.75 \mathrm{E}-05$ & $8.00 \mathrm{E}-05$ \\
\hline 16 & $5.67 \mathrm{e}-002$ & 4.043 & $1.88 \mathrm{E}-03$ & $1.57 \mathrm{E}-02$ & $5.85 \mathrm{e}-002$ & 390.49 & $1.88 \mathrm{E}-05$ & $1.60 \mathrm{E}-04$ \\
\hline 32 & $2.83 \mathrm{e}-002$ & 1.8208 & $1.94 \mathrm{E}-03$ & $3.10 \mathrm{E}-02$ & $3.02 \mathrm{e}-002$ & 97.60 & $1.94 \mathrm{E}-05$ & $3.20 \mathrm{E}-04$ \\
\hline 64 & $1.34 \mathrm{e}-002$ & 1.5446 & $1.97 \mathrm{E}-03$ & $6.00 \mathrm{E}-02$ & $1.53 \mathrm{e}-002$ & 24.434 & $1.97 \mathrm{E}-05$ & $6.39 \mathrm{E}-04$ \\
\hline 128 & $6.17 \mathrm{e}-003$ & 1.1839 & $1.98 \mathrm{E}-03$ & $1.13 \mathrm{E}-01$ & $7.73 \mathrm{e}-003$ & 6.2991 & $1.99 \mathrm{E}-05$ & $1.28 \mathrm{E}-03$ \\
\hline
\end{tabular}

Table 3: Computational results in terms of Maximum absolute errors for different values of $N$ and $\varepsilon$ for example problem- 1

\begin{tabular}{l|lllllll}
\hline$\varepsilon$ & $N=8$ & $N=16$ & $N=32$ & $N=64$ & $N=128$ & $N=256$ & $N=512$ \\
\hline $10^{-4}$ & $1.750 \mathrm{E}-04$ & $1.875 \mathrm{E}-04$ & $1.937 \mathrm{E}-04$ & $1.969 \mathrm{E}-04$ & $1.984 \mathrm{E}-04$ & $1.992 \mathrm{E}-04$ & $1.996 \mathrm{E}-04$ \\
\hline $10^{-6}$ & $1.788 \mathrm{E}-06$ & $1.907 \mathrm{E}-06$ & $1.967 \mathrm{E}-06$ & $1.967 \mathrm{E}-06$ & $2.027 \mathrm{E}-06$ & $2.027 \mathrm{E}-06$ & $2.027 \mathrm{E}-06$ \\
\hline $10^{-8}$ & $0.000 \mathrm{E}+00$ & $0.000 \mathrm{E}+00$ & $0.000 \mathrm{E}+00$ & $0.000 \mathrm{E}+00$ & $0.000 \mathrm{E}+00$ & $0.000 \mathrm{E}+00$ & $0.000 \mathrm{E}+00$ \\
\hline $10^{-10}$ & $0.000 \mathrm{E}+00$ & $0.000 \mathrm{E}+00$ & $0.000 \mathrm{E}+00$ & $0.000 \mathrm{E}+00$ & $0.000 \mathrm{E}+00$ & $0.000 \mathrm{E}+00$ & $0.000 \mathrm{E}+00$ \\
\hline $10^{-15}$ & $0.000 \mathrm{E}+00$ & $0.000 \mathrm{E}+00$ & $0.000 \mathrm{E}+00$ & $0.000 \mathrm{E}+00$ & $0.000 \mathrm{E}+00$ & $0.000 \mathrm{E}+00$ & $0.000 \mathrm{E}+00$ \\
\hline $10^{-25}$ & $0.000 \mathrm{E}+00$ & $0.000 \mathrm{E}+00$ & $0.000 \mathrm{E}+00$ & $0.000 \mathrm{E}+00$ & $0.000 \mathrm{E}+00$ & $0.000 \mathrm{E}+00$ & $0.000 \mathrm{E}+00$ \\
\hline $10^{-30}$ & $0.000 \mathrm{E}+00$ & $0.000 \mathrm{E}+00$ & $0.000 \mathrm{E}+00$ & $0.000 \mathrm{E}+00$ & $0.000 \mathrm{E}+00$ & $0.000 \mathrm{E}+00$ & $0.000 \mathrm{E}+00$ \\
\hline
\end{tabular}

Table 4: Comparison of computational results(MAE) with existing results for various values of $\varepsilon$ and $N$ for example problem2.

\begin{tabular}{l|lll|lll}
\hline & \multicolumn{3}{|c|}{$\varepsilon=10^{-4}$} & \multicolumn{3}{c}{$\varepsilon=10^{-8}$} \\
\hline$N \downarrow$ & $\begin{array}{l}\text { Reddy and } \\
\text { Mohapatra[29] }\end{array}$ & $\begin{array}{l}\text { Mohapatra and } \\
\text { Reddy[17] }\end{array}$ & Our Result & $\begin{array}{l}\text { Reddy and } \\
\text { Mohapatra[29] }\end{array}$ & $\begin{array}{l}\text { Mohapatra and } \\
\text { Reddy[17] }\end{array}$ & Our Result \\
\hline 16 & $1.962 \mathrm{e}-2$ & $1.9628 \mathrm{e}-2$ & $2.7067 \mathrm{E}-04$ & $1.962 \mathrm{e}-2$ & $1.9623 \mathrm{e}-2$ & $2.7067 \mathrm{E}-04$ \\
\hline 32 & $1.031 \mathrm{e}-2$ & $1.0315 \mathrm{e}-2$ & $7.4089 \mathrm{E}-05$ & $1.031 \mathrm{e}-2$ & $1.0311 \mathrm{e}-2$ & $7.4089 \mathrm{E}-05$ \\
\hline 64 & $5.284 \mathrm{e}-3$ & $5.2847 \mathrm{e}-3$ & $1.9491 \mathrm{E}-05$ & $5.284 \mathrm{e}-3$ & $5.2842 \mathrm{e}-3$ & $1.9491 \mathrm{E}-05$ \\
\hline 128 & $2.675 \mathrm{e}-3$ & $2.6759 \mathrm{e}-3$ & $5.0664 \mathrm{E}-06$ & $2.675 \mathrm{e}-3$ & $2.6755 \mathrm{e}-3$ & $5.0664 \mathrm{E}-06$ \\
\hline 256 & $1.344 \mathrm{e}-3$ & $1.3444 \mathrm{e}-3$ & $1.6689 \mathrm{E}-06$ & $1.344 \mathrm{e}-3$ & $1.3440 \mathrm{e}-3$ & $1.6689 \mathrm{E}-06$ \\
\hline 512 & $6.754 \mathrm{e}-4$ & $6.7549 \mathrm{e}-4$ & $2.3842 \mathrm{E}-07$ & $6.754 \mathrm{e}-4$ & $6.7547 \mathrm{e}-4$ & $2.3842 \mathrm{E}-07$ \\
\hline
\end{tabular}


Table 5: Computational results in terms of Maximum absolute errors for different values of $N$ and $\varepsilon$ for example problem- 2

\begin{tabular}{l|lllllll}
\hline$\varepsilon$ & $N=8$ & $N=16$ & $N=32$ & $N=64$ & $N=128$ & $N=256$ & $N=512$ \\
\hline $10^{-4}$ & $9.033 \mathrm{E}-04$ & $2.707 \mathrm{E}-04$ & $7.409 \mathrm{E}-05$ & $1.949 \mathrm{E}-05$ & $5.066 \mathrm{E}-06$ & $1.669 \mathrm{E}-06$ & $2.384 \mathrm{E}-07$ \\
\hline $10^{-6}$ & $9.033 \mathrm{E}-04$ & $2.707 \mathrm{E}-04$ & $7.409 \mathrm{E}-05$ & $1.949 \mathrm{E}-05$ & $5.066 \mathrm{E}-06$ & $1.669 \mathrm{E}-06$ & $2.384 \mathrm{E}-07$ \\
\hline $10^{-8}$ & $9.033 \mathrm{E}-04$ & $2.707 \mathrm{E}-04$ & $7.409 \mathrm{E}-05$ & $1.949 \mathrm{E}-05$ & $5.066 \mathrm{E}-06$ & $1.669 \mathrm{E}-06$ & $2.384 \mathrm{E}-07$ \\
\hline $10^{-10}$ & $9.033 \mathrm{E}-04$ & $2.707 \mathrm{E}-04$ & $7.409 \mathrm{E}-05$ & $1.949 \mathrm{E}-05$ & $5.066 \mathrm{E}-06$ & $1.669 \mathrm{E}-06$ & $2.384 \mathrm{E}-07$ \\
\hline $10^{-15}$ & $9.033 \mathrm{E}-04$ & $2.707 \mathrm{E}-04$ & $7.409 \mathrm{E}-05$ & $1.949 \mathrm{E}-05$ & $5.066 \mathrm{E}-06$ & $1.669 \mathrm{E}-06$ & $2.384 \mathrm{E}-07$ \\
\hline $10^{-25}$ & $9.033 \mathrm{E}-04$ & $2.707 \mathrm{E}-04$ & $7.409 \mathrm{E}-05$ & $1.949 \mathrm{E}-05$ & $5.066 \mathrm{E}-06$ & $1.669 \mathrm{E}-06$ & $2.384 \mathrm{E}-07$ \\
\hline $10^{-30}$ & $9.033 \mathrm{E}-04$ & $2.707 \mathrm{E}-04$ & $7.409 \mathrm{E}-05$ & $1.949 \mathrm{E}-05$ & $5.066 \mathrm{E}-06$ & $1.669 \mathrm{E}-06$ & $2.384 \mathrm{E}-07$ \\
\hline
\end{tabular}

Table 6: Comparison of computational results (MAE) with existing results for various values of $\varepsilon$ and $N$ for example problem3 .

\begin{tabular}{l|lll|lll}
\hline & \multicolumn{3}{|c|}{$\varepsilon=10^{-4}$} & \multicolumn{3}{c}{$\varepsilon=10^{-8}$} \\
\hline$N \downarrow$ & $\begin{array}{l}\text { Mohapatra and } \\
\text { Mahalik[16] }\end{array}$ & $\begin{array}{l}\text { Mohapatra and } \\
\text { Reddy[17] }\end{array}$ & Our Result & $\begin{array}{l}\text { Mohapatra and } \\
\text { Mahalik[16] }\end{array}$ & $\begin{array}{l}\text { Mohapatra and } \\
\text { Reddy[17] }\end{array}$ & Our Result \\
\hline 16 & $1.1143 \mathrm{e}-2$ & $1.1143 \mathrm{e}-2$ & $1.5593 \mathrm{E}-04$ & $1.1141 \mathrm{e}-2$ & $1.1141 \mathrm{e}-2$ & $1.1960 \mathrm{E}-04$ \\
\hline 32 & $5.6345 \mathrm{e}-3$ & $5.6345 \mathrm{e}-2$ & $6.6429 \mathrm{E}-05$ & $5.6343 \mathrm{e}-3$ & $5.6343 \mathrm{e}-2$ & $2.9892 \mathrm{E}-05$ \\
\hline 64 & $2.8197 \mathrm{e}-3$ & $2.8197 \mathrm{e}-3$ & $4.5240 \mathrm{E}-05$ & $2.8192 \mathrm{e}-3$ & $2.8192 \mathrm{e}-3$ & $7.5400 \mathrm{E}-06$ \\
\hline 128 & $1.3958 \mathrm{e}-3$ & $1.3958 \mathrm{e}-3$ & $3.8445 \mathrm{E}-05$ & $1.3955 \mathrm{e}-3$ & $1.3955 \mathrm{e}-3$ & $1.6689 \mathrm{E}-06$ \\
\hline 256 & $6.8346 \mathrm{e}-4$ & $6.8346 \mathrm{e}-4$ & $3.9727 \mathrm{E}-05$ & $6.8342 \mathrm{e}-4$ & $6.8342 \mathrm{e}-4$ & $5.3644 \mathrm{E}-07$ \\
\hline 512 & $3.2758 \mathrm{e}-4$ & $3.2758 \mathrm{e}-4$ & $4.4465 \mathrm{E}-05$ & $3.2754 \mathrm{e}-4$ & $3.2754 \mathrm{e}-4$ & $3.2783 \mathrm{E}-07$ \\
\hline
\end{tabular}

Table 7: Comparison of computational results(MAE) with existing results [ with fitting factor(w.f.f.) and without fitting factor(w.o.f.f.)] for various values of $\varepsilon$ and $N$ for example problem-3.

\begin{tabular}{|c|c|c|c|c|c|c|c|c|}
\hline & \multicolumn{4}{|c|}{$\varepsilon=10^{-3}$} & \multicolumn{4}{|l|}{$\varepsilon=10^{-5}$} \\
\hline & \multicolumn{2}{|c|}{$\begin{array}{l}\text { SOUJANYA } \\
\text { et.al.[18] }\end{array}$} & \multicolumn{2}{|c|}{ Our Result } & \multicolumn{2}{|c|}{$\begin{array}{l}\text { SOUJANYA } \\
\text { et.al.[18] }\end{array}$} & \multicolumn{2}{|c|}{ Our Result } \\
\hline$N \downarrow$ & with f.f & w.o. f.f & with f.f & w.o. f.f & with f.f & w.o. f.f & with f.f & without f.f \\
\hline 8 & $2.02 \mathrm{e}-02$ & $1.23 \mathrm{e}+00$ & $8.41 \mathrm{E}-04$ & $6.97 \mathrm{E}-03$ & $2.06 \mathrm{e}-02$ & $1.39 \mathrm{e}+00$ & $4.79 \mathrm{E}-04$ & $4.62 \mathrm{E}-04$ \\
\hline 16 & $1.06 \mathrm{e}-02$ & $1.04 \mathrm{e}+00$ & $4.87 \mathrm{E}-04$ & $1.51 \mathrm{E}-02$ & $1.10 \mathrm{e}-02$ & $1.42 \mathrm{e}+00$ & $1.23 \mathrm{E}-04$ & 1.19E-04 \\
\hline 32 & $5.27 \mathrm{e}-03$ & $8.67 \mathrm{e}-01$ & $3.97 \mathrm{E}-04$ & $3.05 \mathrm{E}-02$ & $5.63 e-03$ & $1.42 \mathrm{e}+00$ & $3.35 \mathrm{E}-05$ & $2.85 \mathrm{E}-04$ \\
\hline 64 & $2.48 \mathrm{e}-03$ & $7.61 \mathrm{e}-01$ & $3.74 \mathrm{E}-04$ & $5.97 \mathrm{E}-02$ & $2.84 \mathrm{e}-03$ & $1.36 \mathrm{e}+00$ & $1.17 \mathrm{E}-05$ & $6.27 \mathrm{E}-04$ \\
\hline 128 & $1.06 \mathrm{e}-03$ & $5.89 \mathrm{e}-01$ & $3.68 \mathrm{E}-04$ & $1.13 \mathrm{E}-01$ & $1.42 \mathrm{e}-03$ & $1.20 \mathrm{e}+00$ & $4.71 \mathrm{E}-06$ & $1.27 \mathrm{E}-03$ \\
\hline
\end{tabular}

Table 8: Computational results in terms of Maximum absolute errors for different values of $N$ and $\varepsilon$ for example problem- 3

\begin{tabular}{l|lllllll}
\hline$\varepsilon$ & $N=8$ & $N=16$ & $N=32$ & $N=64$ & $N=128$ & $N=256$ & $N=512$ \\
\hline $10^{-4}$ & $5.122 \mathrm{E}-04$ & $1.559 \mathrm{E}-04$ & $6.643 \mathrm{E}-05$ & $4.524 \mathrm{E}-05$ & $3.845 \mathrm{E}-05$ & $3.973 \mathrm{E}-05$ & $4.447 \mathrm{E}-05$ \\
\hline $10^{-6}$ & $4.763 \mathrm{E}-04$ & $1.200 \mathrm{E}-04$ & $2.989 \mathrm{E}-05$ & $7.540 \mathrm{E}-06$ & $1.669 \mathrm{E}-06$ & $5.364 \mathrm{E}-07$ & $3.278 \mathrm{E}-07$ \\
\hline $10^{-8}$ & $4.758 \mathrm{E}-04$ & $1.196 \mathrm{E}-04$ & $2.989 \mathrm{E}-05$ & $7.540 \mathrm{E}-06$ & $1.669 \mathrm{E}-06$ & $5.364 \mathrm{E}-07$ & $3.278 \mathrm{E}-07$ \\
\hline $10^{-10}$ & $4.758 \mathrm{E}-04$ & $1.196 \mathrm{E}-04$ & $2.989 \mathrm{E}-05$ & $7.540 \mathrm{E}-06$ & $1.669 \mathrm{E}-06$ & $5.364 \mathrm{E}-07$ & $3.278 \mathrm{E}-07$ \\
\hline $10^{-15}$ & $4.758 \mathrm{E}-04$ & $1.196 \mathrm{E}-04$ & $2.989 \mathrm{E}-05$ & $7.540 \mathrm{E}-06$ & $1.669 \mathrm{E}-06$ & $5.364 \mathrm{E}-07$ & $3.278 \mathrm{E}-07$ \\
\hline $10^{-25}$ & $4.758 \mathrm{E}-04$ & $1.196 \mathrm{E}-04$ & $2.989 \mathrm{E}-05$ & $7.540 \mathrm{E}-06$ & $1.669 \mathrm{E}-06$ & $5.364 \mathrm{E}-07$ & $3.278 \mathrm{E}-07$ \\
\hline $10^{-30}$ & $4.758 \mathrm{E}-04$ & $1.196 \mathrm{E}-04$ & $2.989 \mathrm{E}-05$ & $7.540 \mathrm{E}-06$ & $1.669 \mathrm{E}-06$ & $5.364 \mathrm{E}-07$ & $3.278 \mathrm{E}-07$ \\
\hline
\end{tabular}


results. Comparisons show that the proposed scheme is better than the schemes presented in the articles[16,17,29,18]. One can easily observed from these Tables:2,3,6 and 9 that the presented fitted scheme is capable of producing highly accurate uniformly convergent solution for any fixed value of step size $N=1 / h>\varepsilon$, when perturbation parameter $\varepsilon \rightarrow 0$. The main feature of the proposed fitted scheme is that it does not depends on the very fine mess size.

\section{References:}

[1] R.R. Gold, Magneto hydrodynamic pipe flow. Part I, Journal of Fluid Mechanics, 13, 1962, pp.505-512.

[2] J. J. H.Miller, R. E. O Riordan, G. I.Shishkin, Fitted Numerical Methods for Singular Perturbation Problems, Error Estimates in the Maximum Norm for Linear Problems in One and Two Dimensions, World Scientific 1996.

[3] H. G.Roos, M.Stynes, L.Tobiska, Numerical Methods for Singularly Perturbed Differential Equations, Springer, Berlin 1996.

[4] E.J.Hinch, Perturbation Methods, Cambridge University Press, Cambridge 1991.

[5] M.H.Holmes, Introduction to Perturbation Methods, Springer, Berlin 1995.

[6] F.Verhulst, Methods and Applications of Singular Perturbations: Boundary Layers and Multiple Timescale Dynamics, Springer, Berlin 2005.

[7] E. P.Doolan, J. J. H.Miller, W. H. A.Schilders, Uniform Numerical methods for problems with initial and boundary layers, Boole 1980.

[8] J.Kevorkian, J. D. Cole, Perturbation Methods in Applied Mathematics, Springer 1981.

[9] A. H. Nayfeh, Perturbation Methods, Wiley 1979.

[10] R. E. OMalley, Introduction to Singular Perturbations, Academic Press, New York 1974.

[11] C. M.Bender, S. A.Orszag, Advanced Mathematical Methods for Scientists and Engineers, McGraw-Hill, New York 1978.

[12] P. A.Farrell, A. F., Hegarty, J. J. H.Miller, E.O Riordan, G.I.Shishkin, Robust Computational Techniques for Boundary Layers. Chapman Hall/CRC Press, Boca Raton, FL 2000.

[13] J. J. H.Miller, E.O Riordan, G. I.Shishkin, Fitted Numerical Methods for Singular Perturbation Problems (revised edition), World Scientific, Singapore 2012.

[14] J.Kevorkian,J. D.Cole, Multiple Scale and Singular Perturbation Methods, Springer-Verlag, New York 1996.

[15] G. I.Shishkin, L. P.Shishkina, Difference Methods For Singular Perturbation Problems, CRC Press, Boca Raton 2009.
[16] J.Mohapatra, M. K. Mahalik, An efficient numerical method for singularly perturbed second order ordinary differential equation, Journal of Mathematical Modeling, 3, 2015, pp. 33-48.

[17] J.Mohapatra, R. N.Reddy, Exponentially Fitted Finite Difference Scheme For Singularly Perturbed Two Point Boundary Value Problems, Int. J. Appl. Comput. Math, 1, 2014, pp. 267-278.

[18] GBSL. Soujanya, K. Phaneendra, Y. N. Reddy, An Exponentially Fitted Non Symmetric Finite Difference Method for Singular Perturbation Problems, Wseas Transactions on Mathematics, 12(7), 2013, pp. 767-776.

[19] P. Chakravarthy, Y. N.Reddy, Exponentially fitted modified upwind scheme for singular perturbation problems, Int J Fluid Mech Res., 33, 2006, pp. 119136.

[20] H. M. Habib,, E. R. El-Zahar, An algorithm for solving singular perturbation problems with mechanization, Appl. Math. Comput., 188, 2007, pp. 286302.

[21] J. Jayakumar, N. Ramanujam, A numerical method for singular perturbation problems arising in chemical reactor theory, Comput. Math. Appl., 27, 1994, pp. 8399.

[22] M. K. Kadalbajoo, D. Kumar, Initial value technique for singularly perturbed two point boundary value problems using an exponentially fitted finite difference scheme, Comput. Math. Appl., 57, 2009, pp. 11471156.

[23] J. Vigo-Aguiar, S. Natesan, An efficient numerical method for singular perturbation problems, J. Comput. Appl. Math., 192, 2006, pp. 132141.

[24] M. K. Kadalbajoo, D. Kumar, A brief survey on numerical methods for solving singularly perturbed problems, Appl. Math. Comput., 217, 2010, pp. 36413716.

[25] R. Ranjan, H. S. Prasad, An Efficient Method of Numerical Integration for a Class of Singularly Perturbed Two Point Boundary Value Problems, WSEAS Transactions on Mathematics, 17, 2018, pp. 265-273.

[26] R. Ranjan, H. S. Prasad, MD. J. Alam, A Simple Method of Numerical Integration For a Class of Singularly Perturbed Two Point Boundary Value Problems, i-managers Journal on Mathematics, 7(1), 2018, pp. 43-52. https://doi.org/10.26634/jmat.7.1.14031

[27] R. Ranjan, H. S. Prasad, A Fitted Finite Difference Scheme for solving Singularly Perturbed Two Point Boundary Value Problems, Information Sciences Letters, 9(2), 2020, pp. 65-73.

[28] T. Aziz, A. Khan, A spline method for secondorder singularly perturbed boundary value problems, Journal of Computational and Applied Mathematics, 147(2), 2002, pp. 445-452. 
[29] N. R. Reddy, J. Mohapatra, An Efficient Numerical Method for Singularly Perturbed Two Point Boundary Value Problems Exhibiting Boundary Layers, Natl. Acad. Sci. Lett., 38(4), 2015, pp. 355359.
Creative Commons Attribution License 4.0 (Attribution 4.0 International, CC BY 4.0)

This article is published under the terms of the Creative Commons Attribution License 4.0

https://creativecommons.org/licenses/by/4.0/deed.en_US 